\title{
A Data Set to Verify Volume and Sample Removal Correction Calculations for Dissolution Testing
}

Alger Salt

Sal Mea Pharmaceutical Consulting, Durham, NC, USA

e-mail: Algersalt@gmail.com

\section{ABSTRACT}

Software in the form of a spreadsheet, computer program, or web-based application is typically used to perform the appropriate mathematical corrections to dissolution profile data to correct for the amount of sample solution removed from the dissolution vessels at each time interval. Because the sample solutions contain analyte and because removal changes the volume of dissolution medium remaining in the vessels, such corrections are sometimes necessary to determine accurate values. This article presents results from a mental exercise where a theoretical dissolution profile was constructed. These data can be used to verify the accuracy of such calculations.

KEYWORDS: Dissolution sample removal correction, dissolution profile data, dissolution test calculations

\section{INTRODUCTION}

$\mathrm{n}$ vitro release and dissolution tests are routinely used to assess the performance of pharmaceutical formulations. In some cases a single data point provides an acceptable level of information for the test. In other cases several data points are needed to yield a profile that shows the amount of drug released from the formulation over time. The shape of the profile and the amount of drug released at one or more intervals may be important indicators of the formulation's performance.

In a typical dissolution test, sample solutions are collected from the vessels, filtered, put into test tubes or suitable vials, then taken to an analytical instrument to measure and determine the amounts of drug released. The cumulative amount of drug and medium withdrawn and removed from the dissolution vessel at each sample interval may be significant enough to affect results in subsequent sample intervals. The effect is more significant when larger volumes are removed from the dissolution vessel. Likewise, the effect is more pronounced for lower initial media volumes. Also, the number of sample collection intervals contributes to this cumulative effect. Mathematical corrections must be applied to determine accurate values, i.e., the values that would have been measured had very little or no sample solution been removed from the vessels (1).

The computations can be done manually with pen and paper but software (whether in the form of a spreadsheet, a stand-alone computer program, or a web-based application) is typically used for this purpose. Presented here are data and results that can be used to verify the accuracy of the numeric values produced by such software. Note that regulations defined in 21CFR11 and EU Annex 11 stipulate other aspects to consider to realize a compliant software application of this nature such as security, version control, and data integrity $(2,3)$.

\section{THE CALCULATIONS}

Consider two different scenarios - one where the amount of solution withdrawn at each sample interval is replaced and the vessel is replenished with an equal volume of fresh medium. (This might be important, for example, if the solubility of the drug is such that without replenishment the remaining media volume would be less than that required for sink conditions.) In this case, the vessel volume remains constant throughout the dissolution test and the correction accounts for the amount of drug removed at each sample interval. Equation 1 can be applied when fresh media replaces the amount of sample removed at each interval.

$$
C_{n, \text { corr }}=C_{n}+\frac{V_{s}}{V_{m}} \int_{i=1}^{n-1} C_{i}
$$

where $C_{n, \text { corr }}$ is the corrected concentration at sample interval $n ; C_{n}$ is the measured or uncorrected concentration at sample interval $n ; V_{m}$ is the original media volume in the dissolution vessel; $V_{s}$ is the volume of sample removed at each time interval; and $C_{i}$ is the uncorrected concentration at each previous sample interval $i$. 
In the other scenario, which perhaps is more common, samples are removed and the vessels are not replenished with media. In this case the correction must account for the amount of drug removed at each interval and for the volume of sample withdrawn because the subsequent volume left in the vessel has been reduced by that amount. Equation 2 can be applied when media replacement is not done.

$$
C_{n, \text { corr }}=\frac{V_{m}-V_{s}(\mathrm{n}-1)}{V_{m}} C_{n}+\frac{V_{s}}{V_{m}} \int_{i=1}^{n-1} C_{i}
$$

Equation 3 combines Equations 1 and 2 to represent both scenarios.

$$
C_{n, \text { corr }}=\frac{V_{m}-\left(V_{s}-V_{r}\right)(n-1)}{V_{m}} C_{n}+\frac{V_{s}}{V_{m}} \int_{i=1}^{n-1} C_{i}
$$

where $V_{r}$ is the volume of media replaced at each sample interval.

If media is not replaced, then replacement volume $V_{r}$ is set to zero and Equation 3 reduces to Equation 2. If media is replaced by a volume equal to the sample volume, then $V_{r}$ equals $V_{s}$ and Equation 3 reduces to Equation 1. Note that Equation 3 could be used if there is ever a case in which the replacement volume was different from the sample volume.

\section{ASSUMPTIONS}

For the purpose of this thought experiment, the following assumptions are made:

- The initial volume of medium in the dissolution vessel is $500 \mathrm{~mL}$.

- The volume of sample removed at each collection interval is $10 \mathrm{~mL}$.

- Six samples are removed from the vessels at equally spaced intervals of 15 minutes for 90 minutes total.

- Withdrawing sample and replenishing with medium has no effect on the hydrodynamics.

- The test formulation contains $60 \mathrm{mg}$ of a drug.

- The drug is very highly soluble in the dissolution medium.

- The formulation releases drug in a linear fashion (zero-order) at a rate of $1 \mathrm{mg}$ per minute. (A thin wafer might exhibit this pattern of release because the two surface areas exposed to the medium would remain constant throughout the dissolution test.) Drug is released from the formulation until all of it has been converted from the solid state into the liquid state, at which time the profile plateaus to the level representing
$100 \%$ released. The theoretical dissolution profile is shown graphically in Figure 1.

Note that the sample volume listed above is the same as that dispensed into collection container, which is typically a vial or test tube. Many dissolution testers incorporate automated sampling, and typically a volume of sample solution equivalent to two to three times the tubing volume is delivered to waste prior to collection. This is done to ensure that the lines and filters are flushed with sample solution to minimize carryover from what previously filled those lines. In this case the entire volume, the amount collected plus the rinse volume, would be counted as the volume removed from the vessel.

\section{DISSOLUTION TEST WITH NO MEDIA REPLACEMENT}

We begin this mental experiment using the scenario where each sample withdrawal is not accompanied by media replacement. Note that for the purpose of this exercise all intermediate results are rounded and expressed to 5 places after the decimal. Any and all rounding errors are propagated through all subsequent intervals. Rounding to five places ensures that the final percent dissolved values are correctly displayed to two places beyond the decimal. The results are summarized in Table 1.

At 15 minutes, $15 \mathrm{mg}$ of the drug has been released and $45 \mathrm{mg}$ of drug in the solid state now remains in the formulation. The vessel contains $500 \mathrm{~mL}$, so the concentration of drug in solution is $15 \mathrm{mg} / 500 \mathrm{~mL}=$ $0.03000 \mathrm{mg} / \mathrm{mL}$. A $10-\mathrm{mL}$ aliquot of sample solution is withdrawn from the vessel, so the amount of drug removed at this interval is $10 \mathrm{~mL} \times 0.03000 \mathrm{mg} / \mathrm{mL}=$ $0.30000 \mathrm{mg}$. The amount of drug in solution is $15 \mathrm{mg}-$ $0.30000 \mathrm{mg}=14.70000 \mathrm{mg}$. The vessel volume is now $490 \mathrm{~mL}$.

At 30 minutes, another $15 \mathrm{mg}$ of drug has been released and now $30 \mathrm{mg}$ of drug in the solid state remains in the formulation. The $14.70000 \mathrm{mg}$ that remained in the vessel from the previous interval means that the total amount of drug in the vessel is now $15 \mathrm{mg}+14.70000$ $\mathrm{mg}=29.7 \mathrm{mg}$. The vessel contains $490 \mathrm{~mL}$, so the drug concentration is $29.70000 \mathrm{mg} / 490 \mathrm{~mL}=0.06061 \mathrm{mg} /$ $\mathrm{mL}$. A $10-\mathrm{mL}$ aliquot of sample solution is withdrawn from the vessel, so the amount of drug removed at this interval is $10 \mathrm{~mL} \times 0.06061 \mathrm{mg} / \mathrm{mL}=0.60610 \mathrm{mg}$. The amount of drug in solution is $29.70000 \mathrm{mg}-0.60610 \mathrm{mg}=29.09390$ $\mathrm{mg}$. The vessel volume is now $480 \mathrm{~mL}$.

At 45 minutes, another $15 \mathrm{mg}$ of drug has been released and now $15 \mathrm{mg}$ of drug in the solid state remains in the 


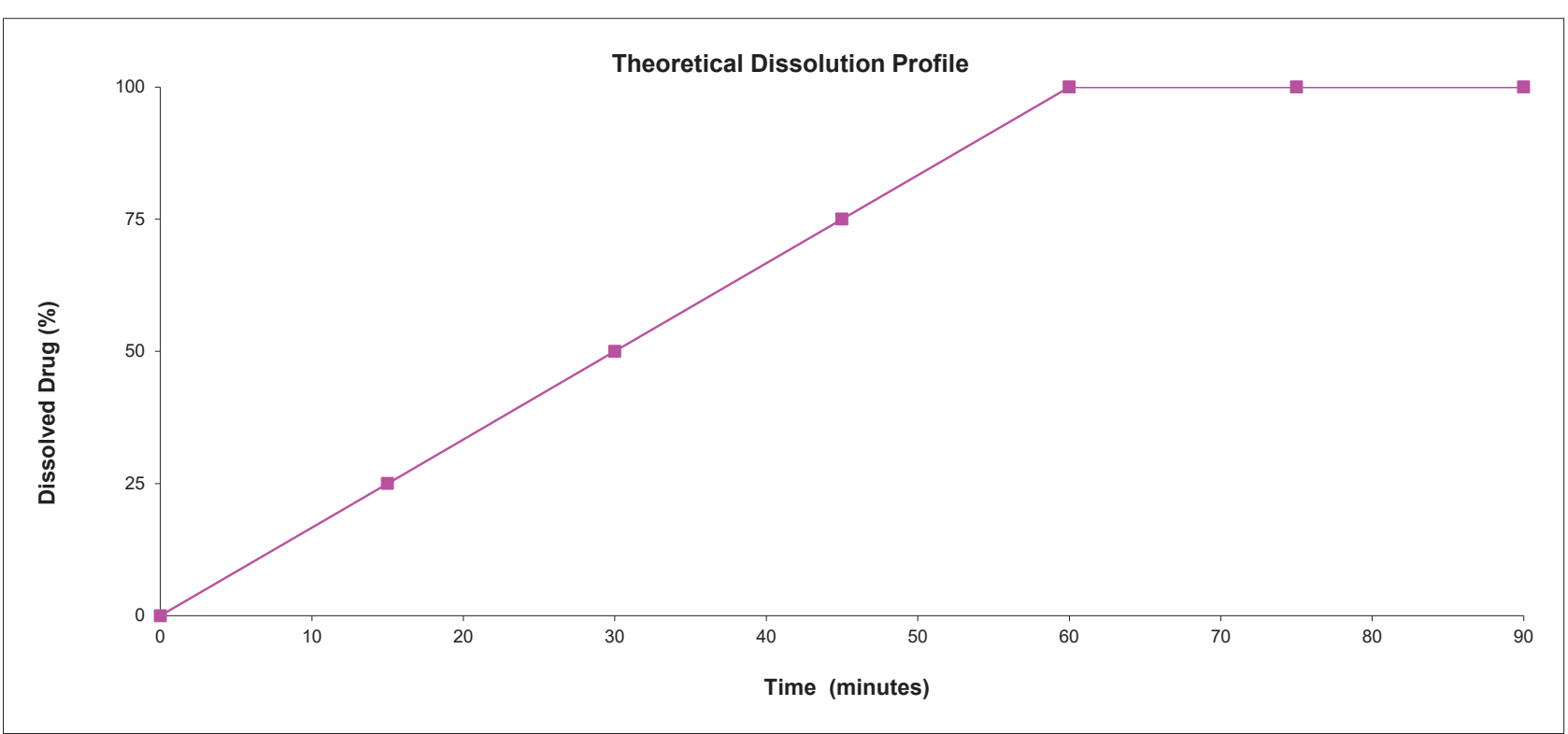

Figure 1. Theoretical dissolution profile.

Table 1. Example Dissolution Test with No Media Replacement

\begin{tabular}{|c|c|c|c|c|c|c|c|c|c|}
\hline $\begin{array}{c}\text { Time } \\
(\mathbf{m i n})\end{array}$ & $\begin{array}{c}\text { Solid } \\
\text { State } \\
(\mathbf{m g})\end{array}$ & $\begin{array}{c}\text { Amount } \\
\text { Released } \\
(\mathbf{m g})\end{array}$ & $\begin{array}{c}\text { From Prev } \\
\text { Interval }(\mathbf{m g})\end{array}$ & $\begin{array}{c}\text { Total for this } \\
\text { Interval }(\mathbf{m g})\end{array}$ & $\begin{array}{c}\text { Vessel } \\
\text { Vol } \\
(\mathrm{mL})\end{array}$ & $\begin{array}{c}\text { Actual Conc. } \\
(\mathbf{m g} / \mathrm{mL})\end{array}$ & $\begin{array}{c}\text { Amount } \\
\text { Removed (mg) }\end{array}$ & $\begin{array}{c}\text { Amount } \\
\text { Remaining (mg) }\end{array}$ & $\begin{array}{c}\% \text { Released } \\
(\text { Uncorrected) }\end{array}$ \\
\hline 15 & 45 & 15 & 0.00000 & 15.00000 & 500 & 0.03000 & 0.30000 & 14.70000 & 25.00000 \\
\hline 30 & 30 & 15 & 14.70000 & 29.70000 & 490 & 0.06061 & 0.60610 & 29.09390 & 50.50833 \\
\hline 45 & 15 & 15 & 29.09390 & 44.09390 & 480 & 0.09186 & 0.91860 & 43.17530 & 76.55000 \\
\hline 60 & 0 & 15 & 43.17530 & 58.17530 & 470 & 0.12378 & 1.23780 & 56.93750 & 103.15000 \\
\hline 75 & 0 & 0 & 56.93750 & 56.93750 & 460 & 0.12378 & 1.23780 & 55.69970 & 103.15000 \\
\hline 90 & 0 & 0 & 55.69970 & 55.69970 & 450 & 0.12378 & 1.23780 & 54.46190 & 103.15000 \\
\hline
\end{tabular}

Prev, previous; Vol, volume; Conc., concentration

formulation. The $29.09390 \mathrm{mg}$ that remained in the vessel from the previous interval means that the total amount of drug in the vessel is now $15 \mathrm{mg}+29.09390 \mathrm{mg}$ $=44.09390 \mathrm{mg}$. The vessel contains $480 \mathrm{~mL}$, so the drug concentration is $44.09390 \mathrm{mg} / 480 \mathrm{~mL}=0.09186 \mathrm{mg} / \mathrm{mL}$. A $10-\mathrm{mL}$ aliquot of sample solution is withdrawn from the vessel, so the amount of drug removed at this interval is $10 \mathrm{~mL} \times 0.09186 \mathrm{mg} / \mathrm{mL}=0.91860 \mathrm{mg}$. The amount of drug in solution is $44.09390 \mathrm{mg}-0.91860 \mathrm{mg}=43.17530$ $\mathrm{mg}$. The vessel volume is now $470 \mathrm{~mL}$.

At 60 minutes, another $15 \mathrm{mg}$ of drug has been released and now no drug remains in the solid state. The 43.17530 $\mathrm{mg}$ that remained in the vessel from the previous interval means that the total amount of drug in the vessel is now $15 \mathrm{mg}+43.17530 \mathrm{mg}=58.17530 \mathrm{mg}$. The vessel contains $470 \mathrm{~mL}$, so the drug concentration is $58.17530 \mathrm{mg} / 470$ $\mathrm{mL}=0.12378 \mathrm{mg} / \mathrm{mL}$. A $10-\mathrm{mL}$ aliquot of sample solution is withdrawn from the vessel, so the amount of drug removed at this interval is $10 \mathrm{~mL} \times 0.12378 \mathrm{mg} / \mathrm{mL}=$ $1.23780 \mathrm{mg}$. The amount of drug in solution is 58.17530 $\mathrm{mg}-1.23777 \mathrm{mg}=56.93750 \mathrm{mg}$. The vessel volume is now $460 \mathrm{~mL}$.

At 75 minutes, no additional drug has been released so the concentration of drug in solution is $56.93750 \mathrm{mg}$ / $460 \mathrm{~mL}=0.12378 \mathrm{mg} / \mathrm{mL}$. A $10-\mathrm{mL}$ aliquot of sample is withdrawn from the vessel, so the amount of drug removed at this interval is $10 \mathrm{~mL} \times 0.12378=1.23780$ $\mathrm{mg}$. The amount of drug in solution is $56.93750 \mathrm{mg}$. The vessel volume is now $450 \mathrm{~mL}$.

At 90 minutes, no additional drug has been released so the concentration of drug in solution will remain unchanged at $0.12378 \mathrm{mg} / \mathrm{mL}$. A $10-\mathrm{mL}$ aliquot of sample is withdrawn from the vessel, so the amount of drug removed at this interval is $10 \mathrm{~mL} \times 0.12378=1.23780 \mathrm{mg}$.. The amount of drug in solution is $55.69970 \mathrm{mg}$. The final vessel volume is now $440 \mathrm{~mL}$. 
The actual drug concentrations at each interval were converted to uncorrected values (percent of drug release), which are presented in the last column of Table 1 . These are the concentrations that would be determined from analytical measurements. With each interval up until 60 minutes the sample removed reduces the amount of drug remaining in solution while the volume in the vessel is also reduced, which effectively has the opposite effect of raising the concentration at each interval. The effects are mathematically represented in the two terms of Equation 2; the first term is the effect of reducing the vessel volume at each interval and the second term represents the effect of drug removed per interval. The corrected concentrations are obtained by applying Equation 2 (or Equation 3) to the measured concentrations at each interval. Note that the value for percent released at the 60 -minute interval is $103.15 \%$ as opposed to the corrected value of $100.00 \%$.

\section{DISSOLUTION TEST WITH MEDIA REPLACEMENT}

Now consider the case in which media is replaced at each interval. The vessels are replenished with fresh medium after each sample is withdrawn to maintain the vessel volume at $500 \mathrm{~mL}$. The results are summarized in Table 2 .

At 15 minutes, $15 \mathrm{mg}$ of drug has been released and $45 \mathrm{mg}$ of drug in the solid state now remains in the formulation. The concentration of drug in solution is 15 $\mathrm{mg} / 500 \mathrm{~mL}=0.03000 \mathrm{mg} / \mathrm{mL}$. A $10-\mathrm{mL}$ aliquot of sample solution is withdrawn from the vessel, so the amount of drug removed at this interval is $10 \mathrm{~mL} \times 0.03000 \mathrm{mg} / \mathrm{mL}$ $=0.30000 \mathrm{mg}$. The amount of drug in solution is $15 \mathrm{mg}$ $-0.30000 \mathrm{mg}=14.70000 \mathrm{mg}$. The vessel is replenished with $10 \mathrm{~mL}$ of fresh medium.

At 30 minutes, another $15 \mathrm{mg}$ of drug has been released and now $30 \mathrm{mg}$ of drug in the solid state remains in the formulation. The $14.70000 \mathrm{mg}$ that remained in the vessel from the previous interval means that the total amount of drug in the vessel is now $15 \mathrm{mg}+14.70000 \mathrm{mg}$ $=29.70000 \mathrm{mg}$. The drug concentration is $29.70000 \mathrm{mg}$ / $500 \mathrm{~mL}=0.05940 \mathrm{mg} / \mathrm{mL}$. A $10-\mathrm{mL}$ aliquot of sample solution is withdrawn from the vessel, so the amount of drug removed at this interval is $10 \mathrm{~mL} \times 0.05940 \mathrm{mg} / \mathrm{mL}=$ $0.59400 \mathrm{mg}$. The amount of drug in solution is 29.70000 $\mathrm{mg}-0.59400 \mathrm{mg}=29.10600 \mathrm{mg}$. The vessel is replenished with $10 \mathrm{~mL}$ of fresh medium.

At 45 minutes, another $15 \mathrm{mg}$ of drug has been released and now $15 \mathrm{mg}$ of drug in the solid state remains in the formulation. The $29.10600 \mathrm{mg}$ that remained in the vessel from the previous interval means that the total amount of drug in the vessel is now $15 \mathrm{mg}+29.10600 \mathrm{mg}$ $=44.10600 \mathrm{mg}$. The drug concentration is $44.10600 \mathrm{mg}$ / $500 \mathrm{~mL}=0.08821 \mathrm{mg} / \mathrm{mL}$. A $10-\mathrm{mL}$ aliquot of sample solution is withdrawn from the vessel, so the amount of drug removed at this interval is $10 \mathrm{~mL} \times 0.08821 \mathrm{~g} / \mathrm{mL}=$ $0.88210 \mathrm{mg}$. The amount of drug in solution is 44.10600 $\mathrm{mg}-0.88210 \mathrm{mg}=43.22390 \mathrm{mg}$. The vessel is replenished with $10 \mathrm{~mL}$ of fresh medium.

At 60 minutes, another $15 \mathrm{mg}$ of drug has been released and now no drug remains in the solid state. The 43.22390 $\mathrm{mg}$ that remained in the vessel from the previous interval means that the total amount of drug in the vessel is now $15+43.22390=58.22390 \mathrm{mg}$. The drug concentration is $58.22390 \mathrm{mg} / 500 \mathrm{~mL}=0.11645 \mathrm{mg} / \mathrm{mL}$. A $10-\mathrm{mL}$ aliquot of sample solution is withdrawn from the vessel, so the amount of drug removed at this interval is $10 \mathrm{~mL}$ $\times 0.11645 \mathrm{mg} / \mathrm{mL}=1.16450 \mathrm{mg}$. The amount of drug in solution is $58.22390 \mathrm{mg}-1.16450 \mathrm{mg}=57.05940 \mathrm{mg}$. The vessel is replenished with $10 \mathrm{~mL}$ of fresh medium.

At 75 minutes, all of the drug in the solid state has been depleted so no more has been released. The 57.05940 $\mathrm{mg}$ that remained in the vessel from the previous interval means that the concentration is $57.05940 \mathrm{mg} / 500 \mathrm{~mL}$ $=0.11412 \mathrm{mg} / \mathrm{mL}$. A $10-\mathrm{mL}$ aliquot of sample solution is withdrawn from the vessel, so the amount of drug

Table 2. Example Dissolution Test with Media Replacement

\begin{tabular}{|c|c|c|c|c|c|c|c|c|c|}
\hline $\begin{array}{c}\text { Time } \\
(\mathbf{m i n})\end{array}$ & $\begin{array}{c}\text { Solid } \\
\text { State } \\
(\mathbf{m g})\end{array}$ & $\begin{array}{c}\text { Amount } \\
\text { Released } \\
(\mathbf{m g})\end{array}$ & $\begin{array}{c}\text { From Prev } \\
\text { Interval (mg) }\end{array}$ & $\begin{array}{c}\text { Total for this } \\
\text { Interval (mg) }\end{array}$ & $\begin{array}{c}\text { Vessel } \\
\text { Vol } \\
(\mathbf{m L})\end{array}$ & $\begin{array}{c}\text { Actual Conc. } \\
(\mathbf{m g} / \mathrm{mL})\end{array}$ & $\begin{array}{c}\text { Amount } \\
\text { Removed (mg) }\end{array}$ & $\begin{array}{c}\text { Amount } \\
\text { Remaining (mg) }\end{array}$ & $\begin{array}{c}\text { \% Released } \\
(\text { Uncorrected) }\end{array}$ \\
\hline 15 & 45 & 15 & 0.00000 & 15.00000 & 500 & 0.03000 & 0.30000 & 14.70000 & 25.00000 \\
\hline 30 & 30 & 15 & 14.70000 & 29.70000 & 500 & 0.05940 & 0.59400 & 29.10600 & 49.50000 \\
\hline 45 & 15 & 15 & 29.10600 & 44.10600 & 500 & 0.08821 & 0.88210 & 43.22390 & 73.50833 \\
\hline 60 & 0 & 15 & 43.22390 & 58.22390 & 500 & 0.11645 & 1.16450 & 57.05940 & 97.04167 \\
\hline 75 & 0 & 0 & 57.05940 & 57.05940 & 500 & 0.11412 & 1.14120 & 55.91820 & 95.10000 \\
\hline 90 & 0 & 0 & 55.91820 & 55.91820 & 500 & 0.11184 & 1.11840 & 54.79980 & 93.20000 \\
\hline
\end{tabular}

Prev, previous; Vol, volume; Conc., concentration 
removed at this interval is $10 \mathrm{~mL} \times 0.11412 \mathrm{mg} / \mathrm{mL}=$ $1.14120 \mathrm{mg}$. The amount of drug in solution is 57.05940 $\mathrm{mg}-1.14120 \mathrm{mg}=55.91820 \mathrm{mg}$. The vessel is replenished with $10 \mathrm{~mL}$ of fresh medium.

At 90 minutes, all of drug in the solid state has been depleted and no more has been released. The 55.91820 $\mathrm{mg}$ that remained in the vessel from the previous interval means concentration is $55.91820 \mathrm{mg} / 500 \mathrm{~mL}=0.11184$ $\mathrm{mg} / \mathrm{mL}$. A $10-\mathrm{mL}$ aliquot of sample solution is withdrawn from the vessel, so the amount of drug removed at this interval is $10 \mathrm{~mL} \times 0.11184 \mathrm{mg} / \mathrm{mL}=1.11840 \mathrm{mg}$. The amount of drug in solution is $55.91821 \mathrm{mg}-1.11836 \mathrm{mg}$ $=54.79980 \mathrm{mg}$. The vessel is replenished with $10 \mathrm{~mL}$ of fresh medium.

The actual drug concentrations at each interval are expressed as uncorrected values (percent of drug released) in the last column of Table 2 . Note that the percent released at the 60 -minute interval is just over $97 \%$ as opposed to the corrected value of $100 \%$. With each interval the sample solution undergoes successive and cumulative dilutions, so the measured concentrations are lower relative to those that would have been measured without sample removal and media replacement. This effect is represented in the second term of Equations 1-3. The corrected concentrations are obtained by applying Equation 1 (or Eq. 3) to the measured concentrations at each interval.

\section{RESULTS AND DISCUSSION}

Table 3 presents results from a spreadsheet developed to perform the appropriate corrections for dissolution profiles as per Eq. 3. Results from both cases (with and without media replacement) are listed using the data set presented here. As expected, the corrected results exactly match the data in the theoretical profile presented in Figure 1.

Table 3. Measured (Uncorrected) and Corrected Results of
Example Dissolution Tests
\begin{tabular}{|c|c|c|c|c|}
\hline & No Media Replacement & With Media Replacement \\
\hline $\begin{array}{c}\text { Time } \\
(\text { min) }\end{array}$ & $\begin{array}{c}\text { Measured } \\
\% \text { Released }\end{array}$ & $\begin{array}{c}\text { Corrected \% } \\
\text { Released }\end{array}$ & $\begin{array}{c}\text { Measured } \\
\% \text { Released }\end{array}$ & $\begin{array}{c}\text { Corrected \% } \\
\text { Released }\end{array}$ \\
\hline 0 & 0.0000 & 0.00 & 0.0000 & 0.00 \\
\hline 15 & 25.0000 & 25.00 & 25.0000 & 25.00 \\
\hline 30 & 50.5102 & 50.00 & 49.5000 & 50.00 \\
\hline 45 & 76.5519 & 75.00 & 73.5100 & 75.00 \\
\hline 60 & 103.1476 & 100.00 & 97.0398 & 100.00 \\
\hline 75 & 103.1476 & 100.00 & 95.0990 & 100.00 \\
\hline 90 & 103.1476 & 100.00 & 93.1970 & 100.00 \\
\hline
\end{tabular}

\section{CONCLUSION}

The data set presented here may be used by those who need to verify the accuracy of calculations used to correct dissolution profiles for sample aliquot removal. This can be part of a planned software validation effort that would also consider things like security, data integrity, version control, and other aspects decreed by appropriate regulations.

\section{CONFLICTS OF INTEREST}

The author disclosed no conflicts of interest related to this article.

\section{REFERENCES}

1. Harman, A. Correction factor for dissolution profile calculations. J. Pharm. Sci. 1993, 82, 1190. DOI: 10.1002/jps.2600821126.

2. CFR - Code of Federal Regulations Title 21. U.S. Food \& Drug Administration. U.S. Department of Health \& Human Services. https://www.accessdata.fda.gov/scripts/cdrh/cfdocs/cfcfr/ cfrsearch.cfm. Last updated November 10, 2020. Accessed April 6, 2021.

3. EudraLex, The Rules Governing Medicinal Products in the European Union. Good Manufacturing Practice, Medicinal Products for Human and Veterinary Use, Vol 4, Annex 11: Computerized Systems. European Commission, Health and Consumers Directorate-General, SANCO/C8/AM/sl/ ares(2019)1064599, 2011. 